\title{
Photodegradation of Acid Red 183 Dye over Ag-CdS Nanoparticles
}

\author{
MAHENDRASINGH J. PAWAR* and ARCHANA D. INGALE \\ Laboratory of Materials Science, Department of Chemistry, ACS College, Kiran Nagar, \\ Amravati M.S. India 444606 \\ mjpawar09@outlook.com
}

Received 27 February 2016 / Accepted 19 March 2016

\begin{abstract}
We have successfully synthesized Ag-CdS nanoparticles using a hydrothermal method. The obtained materials were characterized by powder X-ray diffraction (XRD), Brunauer-EmmettTeller (BET) surface area method, transmission electron microscopy (TEM) and scanning electron microscopy (SEM). The synthesized materials were used as photocatalyst for degradation of Acid Red 183 dye under visible light irradiation. The experimental results showed that specific surface are, dopant concentration, $\mathrm{pH}$ of dye solution and oxidizing agent affects the rate of dye degradation. The results clearly indicated the photocatalytic activity of CdS effectively improved by Ag doping.
\end{abstract}

Keywords: Ag-CdS, Nanoparticles, Acid Red 183, Photodegradation

\section{Introduction}

Dye pollutants from textile, papers and other industries are important sources of environmental contamination. It is estimated that fifteen percent of the total World dye production is lost during dyeing process and it is released in textile effluents ${ }^{1}$. During the dying process, the colours produced by minute amounts of dyes accidentally released in water are considered to pose serious problems, because they have considerable environmental effects on the water and make them visually unpleasant ${ }^{2}$. Moreover, environmental pollution by organic dyes also sets a severe ecological problem, which is increased by the fact that most of them are often toxic to micro organisms and take a long degradation times in the environment ${ }^{3}$.

Azo dyes are a large class of very effective synthetic organic dyes used for colouring a variety of consumer goods such as foods, cosmetics, carpets, clothes, leather and textiles. Today, azo dyes are produced for the most part in China and India, followed by Korea, Chinese Taipei and Argentina ${ }^{4}$. The azo dyes with $-\mathrm{N}=\mathrm{N}$ group in their molecular structure constitute the makes up to $60-70 \%$ of all textile dyestuffs produced ${ }^{5}$. However, some azo dyes break down during use and release chemicals known as aromatic amines, some of which can cause cancer ${ }^{6}$. 
In recent years advanced oxidation processes (AOPs) using inorganic semiconductors have been effectively used to detoxify recalcitrant pollutants present in industrial wastewater. On exposure to the light, organic molecules on a semiconductor surface can be photochemically oxidized or reduced inhigh chemical yields. Since organic compounds have finite oxidation and reduction potential energies, variable electronic band energy of a semiconductor, which can be simply controlled by decreasing nanoparticle diameter, canmodify the photocatalytic efficiency. Cadmium sulphide is an important semiconductor possessing interesting optical and electronic properties and is being increasingly used as catalysts for various photocatalytic reactions ${ }^{7-9}$. The method of synthesis is found to have apronounced effect on the catalytic activity of CdS. In this study, we report the hydrothermal synthesis of $\mathrm{CdS}$ nanoparticles and its photocatalytic activities for degradation of acid red 183 (AR183) dyes.

\section{Experimenal}

Ag-doped CdS (Ag content 0-2\% mole fraction) $100 \mathrm{~mL}$ of $0.2 \mathrm{M}$ 1-thioglycerol, $0.1 \mathrm{M}$ $\left(\mathrm{NH}_{4}\right)_{2} \mathrm{~S}$ solution and $50 \mathrm{~mL}$ of $0.1 \mathrm{M} \mathrm{NaOH}$ was added slowly to $150 \mathrm{~mL}$ of $0.09 \mathrm{M}$ $\left(\mathrm{Cd}\left(\mathrm{NO}_{3}\right)_{2}\right)$ solution and vigorous stirring was continued for 1 hour. To this solution, calculated amount of silver nitrate was added and the mixture was further stirred for 2 hours. Then the mixture was kept in furnace at $180^{\circ} \mathrm{C}$ for 10 hours and then allowed to cool at room temperature. The light yellow precipitates were centrifuged and washed several times using water and ethanol. The final products were dried at room temperature for 4 hours.

The structural and morphological properties of prepared samples have been studied using XRD, SEM and TEM techniques. The photocatalytic activity of samples was tested for the degradation of AR 183 dye under the condition: $0.5-3 \mathrm{~g} / \mathrm{L}$ catalyst/dye solution ratio, $0.04 \mathrm{M}$ concentration of AR 183 and $2 \mathrm{~h}$ reaction time. The photocatalytic experiments were conducted under ambient atmospheric conditions in a reactor using visible light $(>360 \mathrm{~nm})$ in dark. In order to ensure adsorption equilibrium, the solution was stirred for about $45 \mathrm{~min}$ in dark, prior to irradiation. The apparent kinetics of dye degradation was determined by monitoring the concentration of the substrate using spectrophotometer. The photo degradation efficiency ofthe dye by CdS samples was calculate dusing the Eq. (1):

$$
\% \text { Degradation }=\frac{C-C o}{C o} x 100
$$

where, $\mathrm{C}_{\mathrm{o}}$ and Care the concentration of the AR before and after UV irradiation, respectively.

\section{Results and Discussion}

The XRD patterns also confirmed the formation of CdS. The XRD pattern exhibited diffraction peaks at $26.4^{\circ}, 43.7^{\circ}$ and $51.6^{\circ}$ corresponds to (111), (220), (311) planes of cubic phase CdS nanoparticles. The calculated lattice parameter value for undoped CdS comes out to be $5.870 \AA$ where as for $\mathrm{Ag}$ doped $\mathrm{CdS}$ shows slightly decrease in lattice parameter with increase of $\mathrm{Ag}$ concentration (Table 1). Figure 1 shows the XRD pattern of Ag-CdS (Ag content $1 \%$ mole fraction) nanoparticles. All the diffracted peaks of $\mathrm{CdS}$ nanoparticles are indexed to cubic structure. The broadening of the XRD pattern is larger indicating that the sample is nano-crystalline in nature.The mean crystallite size of Ag-CdS ( $1 \mathrm{~mol} \% \mathrm{Ag}$ ), calculated from the FWHM of the peak $26.4^{\circ}(111)$ was $\sim 9 \mathrm{~nm}$.

To study the morphology of the samples, SEM analysis was performed. The SEM micrograph of the Ag-CdS (Ag content 1\% mole fraction) is shown in Figure 2. It can be seen that the particles adopt irregular morphology with different sized particle. The CdS particles appear highly agglomerated in nature. This might be due to the fact that the crystal growth itself because of the small size regime which is evident from the XRD analysis. 
Table 1. Structural parameters of undoped and Ag doped CdS.

\begin{tabular}{ccccccc}
\hline Sample & $\begin{array}{c}\text { Sample } \\
\text { code }\end{array}$ & Phase & $\begin{array}{c}\text { Specific Surface } \\
\text { Area, } \mathrm{m}^{2} / \mathrm{g}\end{array}$ & $\mathrm{a}(\AA)$ & $\begin{array}{c}\text { Band gap, } \\
\mathrm{eV}\end{array}$ & $\begin{array}{c}\text { Particle } \\
\text { size, } \mathrm{nm}\end{array}$ \\
\hline $\begin{array}{c}\mathrm{CdS} \\
\mathrm{Ag}-\mathrm{CdS},\end{array}$ & CDS & Cubic & 64.56 & 5.870 & 2.40 & 14.4 \\
$\begin{array}{c}1 \mathrm{~mol} \% \mathrm{Ag} \\
\mathrm{Ag}-\mathrm{CdS},\end{array}$ & CDSA1 & Cubic & 77.22 & 5.814 & 2.49 & 9.4 \\
$2 \mathrm{~mol} \% \mathrm{Ag}$ & CDSA & Cubic & 71.01 & 5.805 & 2.54 & 12.6 \\
\hline
\end{tabular}

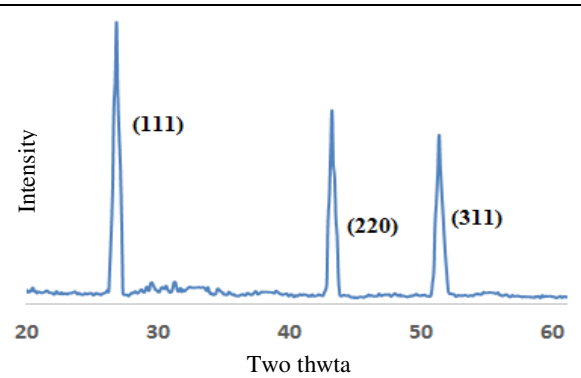

Figure 1. XRD of Ag-CdS (Ag content $1 \%$ mole fraction).

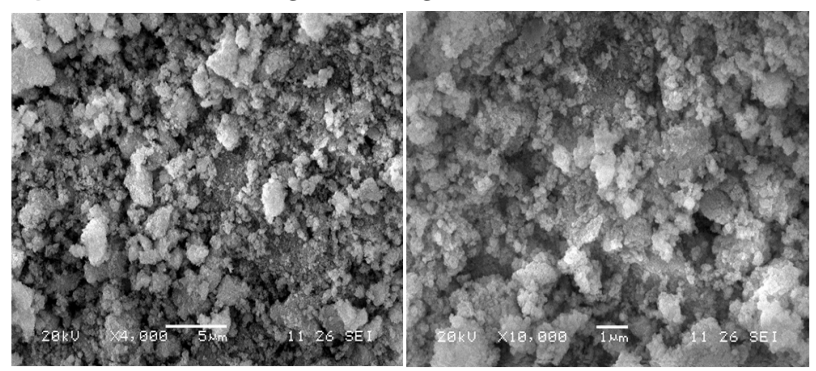

Figure 2. SEM of CDSA1 (1\% mol Ag)

The specific surface area ( $\mathrm{SSA}_{\mathrm{BET}}$ ) of $\mathrm{CdS}$ samples were measured by nitrogen adsorption as shown in Figure 3 and the results clearly showed that $\mathrm{SSA}_{\mathrm{BET}}$ increased with increasing $\mathrm{Ag}$ concentration up to $1 \mathrm{~mol} \%$ and tends to fall with $2 \mathrm{~mol} \%$. It was presumed that, when in excess, the existence of dopant on the CdS surface lessens the specific surface area of catalyst. This prevents the adsorption of reactant and thus, inhibits the photocatalytic activity ${ }^{10}$.

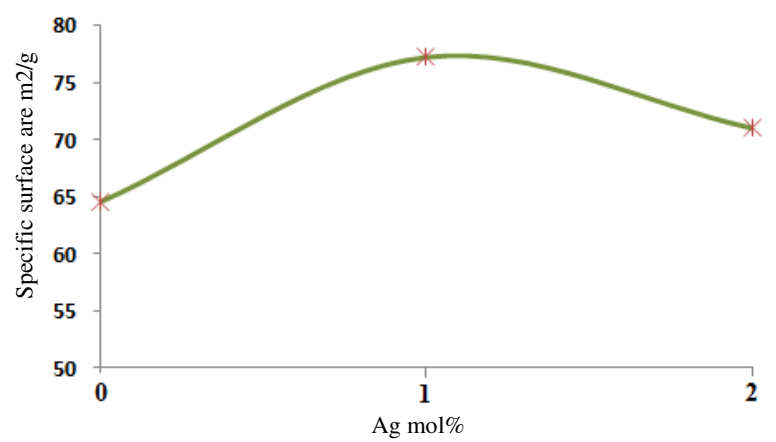

Figure 3. The specific surface area (SSABET) of Ag-doped CdS (Ag content 0-2\% mol fraction) nanoparticles 
Figure 4 shows the relative change in the concentration $\left(C / C_{O}\right)$ of $A R-183$ in the presence and absence of prepared CdS samples as a function of time. A maximum photocatalytic activity is found for CDSA1 which almost completely decolorized the solution in a period of only 90 minutes. Such an increase in photocatalytic activity of CdS could be due to three reasons: one, a decrease in energy to exit electron from conduction band to valence band, two, $\mathrm{Ag}$ deposited on the CdS particles can form a space charge layer, which can separate the photo induced electron-hole pairs and three, the defects produced due to lattice deformation (Table 1) caused by $\mathrm{Ag}$ doping can inhibit the recombination of electron-hole pairs and eventually, enhance the photocatalytic activity. In present study, CDSA1 has the best photoactivity, since it has a band gap of $2.45 \mathrm{eV}$, the lowest particle size and the largest surface area.

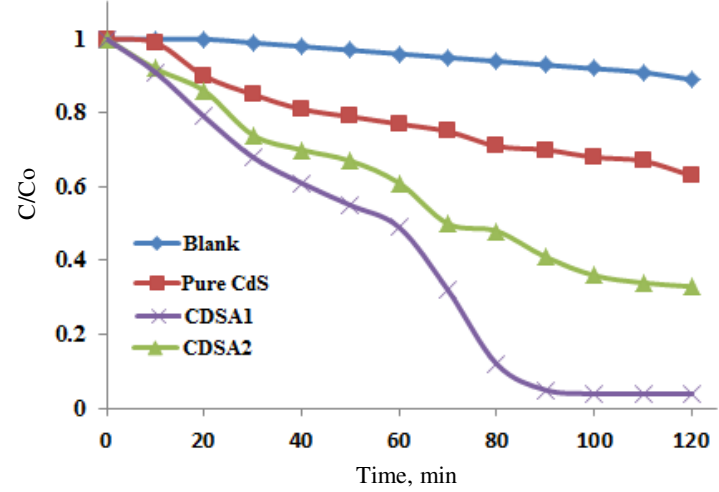

Figure 4. Change in the concentration of AR-183 dye with time in presence and absence of CdS samples

A series of experiments has been carried out to study the effect of $\mathrm{pH}$ on AR183 removal efficiency of the optimized catalyst amounts of sample CDSA1 (i.e. $1.5 \mathrm{~g} / \mathrm{L}$ ) and UV-irradiation times (up to $120 \mathrm{~min}$ ) $\mathrm{pH}$ variation can in fact influence the adsorption of dye molecules onto the catalyst surfaces ${ }^{11}$. The findings are summarized in Table $2 \&$ Figure 5 . The results indicate that increasing the $\mathrm{pH}$ of $\mathrm{AR} 183$ solution from 2 to 8 leads to an increase in dye removal efficiency from 54 to $96.0 \%$, but atpH more than 7 , the AR183 removal efficiency almost remains unchanged. The possible reason for this behavior is that alkaline $\mathrm{pH}$ range favours the formation of more $\mathrm{OH}$ radicals due to the presence of large quantity of $\mathrm{OH}^{-}$ions in the alkaline medium, which enhances the photocatalytic degradation ofAR 183 significantly ${ }^{12}$. The optimum condition for $\mathrm{pH}$ is 7 at which photodegradation percentage of AR183 reach to $96 \%$.

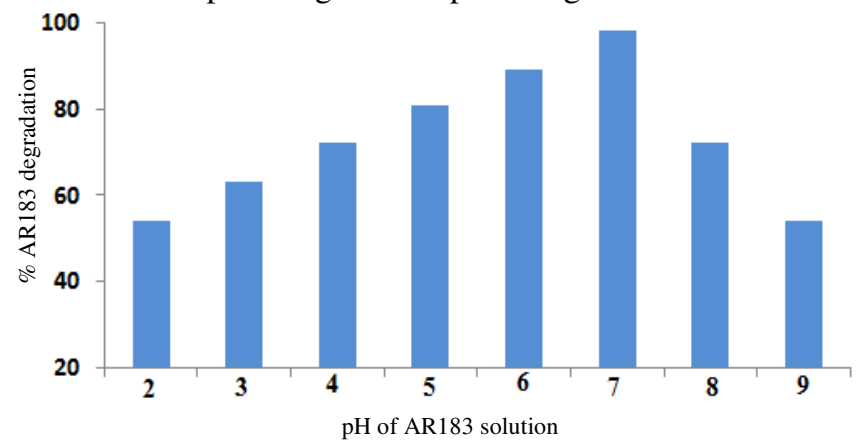

Figure 5. CDSA1 (1.5 g/L) photodegradation efficiency of AR183 dye at different $\mathrm{pH}$ 


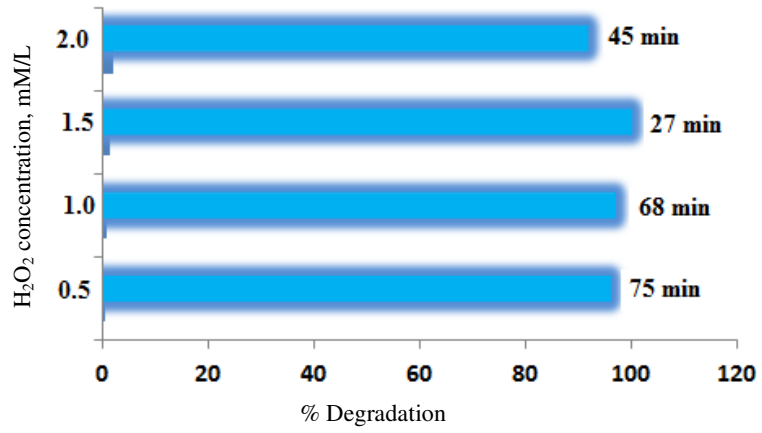

Figure 6. Effect of $\mathrm{H}_{2} \mathrm{O}_{2}$ concentration on degradation efficiency of AR183 (pH=7) over CDSA1. Catalyst (1.5 g/L)

Reports show that, oxidizing agents $\left(\mathrm{H}_{2} \mathrm{O}_{2}, \mathrm{KbrO}_{3},\left(\mathrm{NH}_{4}\right)_{2} \mathrm{~S}_{2} \mathrm{O}_{8}\right.$ etc. $)$ have a great deal of influence on the photocatalytic degradation of dyes. In the present study, the effect of adding $\mathrm{H}_{2} \mathrm{O}_{2}$ on the degradation of AR183 ( $\left.\mathrm{pH}=7\right)$ using CDSA1 is reported. The experiment was conducted at the concentration range $0.5-2 \mathrm{mM} / \mathrm{L} \mathrm{H}_{2} \mathrm{O}_{2}$. From Figure 6, it can be seen that the degradation rate increases with increase in $\mathrm{H}_{2} \mathrm{O}_{2}$ concentration. The results indicated that $1.5 \mathrm{mM} / \mathrm{L}$ was an optimal dosage of $\mathrm{H}_{2} \mathrm{O}_{2}$, at which the degradation efficiency of the AR183 on the CDSA1 attained the height. The $\mathrm{H}_{2} \mathrm{O}_{2}$ acts as a source of ${ }^{\circ} \mathrm{OH}$ radicals by reaction with photogenerated electrons and plays a dual role: as strong oxidants them selves and as electron scavengers (according to equations 2-4), thus inhibiting the electron-hole recombination at the catalyst surface ${ }^{13}$. At higher dosage of $\mathrm{H}_{2} \mathrm{O}_{2}$ beyond the optimum, the degradation efficiency of AR183 decreased. This may be due to consumption of very reactive ${ }^{\circ} \mathrm{OH}$ radicals by $\mathrm{H}_{2} \mathrm{O}_{2}$ itselfas given in eqs. (5) \& (6) ${ }^{14-15}$.

$$
\begin{gathered}
\mathrm{H}_{2} \mathrm{O}_{2}+\mathrm{O}_{2}^{-\cdot} \rightarrow{ }^{\cdot} \mathrm{OH}+\mathrm{OH}^{-}+\mathrm{O}_{2} \\
\mathrm{H}_{2} \mathrm{O}_{2}+h \mathrm{v} \rightarrow 2^{\cdot} \mathrm{OH} \\
\mathrm{H}_{2} \mathrm{O}_{2}+\mathrm{e}_{\mathrm{CB}}^{-} \rightarrow{ }^{\circ} \mathrm{OH}+\mathrm{OH}^{-} \\
\cdot \mathrm{OH}+\mathrm{H}_{2} \mathrm{O}_{2} \rightarrow \mathrm{HO}_{2}^{\cdot}+\mathrm{H}_{2} \mathrm{O} \\
\cdot \mathrm{OH}+\mathrm{HO}_{2}{ }^{\cdot} \rightarrow \mathrm{O}_{2}+\mathrm{H}_{2} \mathrm{O}
\end{gathered}
$$

Stability of the catalyst was tested by carrying out the degradation with the used catalyst. The results for four cycles of the catalyst are shown in Figure 7. The CDSA1 sample exhibited 100, 97.2, 96.3 and 95.4\% degradation in first, second, third and fourth cycles, respectively. These results indicate that CDSA1 catalyst remains effective and reusable under UV light.

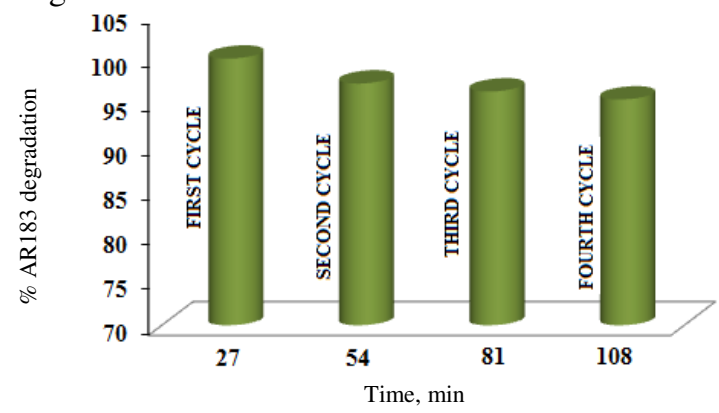

Figure 7. Reusability of CDSA1 catalyst: $[\mathrm{AR} 183]=0.0004 \mathrm{M}, \mathrm{pH}=7, \mathrm{CDSA} 1$ dosage $=$ $1.5 \mathrm{~g} / \mathrm{L}, \mathrm{H}_{2} \mathrm{O}_{2}$ concentration $=1.5 \mathrm{mM} / \mathrm{L}$ 


\section{Conclusion}

Ag-CdS nanoparticles were synthesized by hydrothermal method.The synthesized samples were characterized by XRD, BET, TEM and SEM techniques. The XRD result showed that, the average particle size irregularly decreases with $\mathrm{Ag}$ content which is consistent with SEM images. The synthesized materials were used as photocatalyst in the degradation of acid red 183 dye. The Ag-CdS (1 mol\% Ag) showed the higher degradation percentage and rate at $\mathrm{pH}$ 7. Addition of $\mathrm{H}_{2} \mathrm{O}_{2}$ influences the rate of reaction considerably. The stability of the catalysts was tested by its reuse. This study may leads to improve the research scope in development of visible light driven photocatalysis.

\section{Acknowledgement}

The authors wish to acknowledge the support of this work by University Grant Commission (File No.51172109).We would also like to acknowledge Department of Physics, VidyaBhartiMahavidyalay, Amravati for X-ray diffraction observations.

\section{References}

1. Vautier M, Guillard C and Herrmann J, J Cataly., 2001, 201(1), 46-59; DOI:10.1006/jcat.2001.3232

2. Wang C, Lee C, Lyu M and Juang L, Dyes Pigments, 2008, 76(3), 817-824; DOI:10.1016/j.dyepig.2007.02.004

3. Zainal Z, Hui L K, Hussein M Z, Taufiq-Yap Y H, Abdullah A H and Ramli I, $J$ Hazard Mater., 2005, 125(1-3), 113-120; DOI:10.1016/j.jhazmat.2005.05.013

4. Organisation for Economic Cooperation and Development. Environmental Requirements and Market Access. Chapter 2: Limits on Aromatic Amines in Textiles Coloured with Azo Dyes, 2005, OECD Publishing, ISBN-92-64-01373-3.

5. Habibi M H, Hassanzadeh A and Mahdavi S, J Photochem Photobiol: A Chem., 2005, 172(1), 89-96; DOI:10.1016/j.jphotochem.2004.11.009

6. Dom N, Knapen D, Benoot D, Nobels I and Blust R, Chemosphere, 2010, 81(2), 177 186; DOI:10.1016/j.chemosphere.2010.06.059

7. Kothari S, Kumar A, Vyas R, Ameta R and Punjabi P P, J Brazilian Chem Soc., 2009, 20(10), 1821-1826; DOI:10.1590/S0103-50532009001000008

8. Giribabu K, Suresh R, Manigandan R, Vijayraj A, Prabu R, and Narayanan V, Bull Korean Chem Soc., 2012, 33(9), 2910-2916; DOI:10.5012/bkcs.2012.33.9.2910

9. Pawar M J and Chaure S S, Chalcogenide Lett., 2009, 6(12), 689-693.

10. Liu G, Zhang X, Xu Y, Niu X, Zheng L and Ding X, Chemosphere, 2005, 59(9), 1367-1371; DOI:10.1016/j.chemosphere.2004.11.072

11. Wang N, Li J, Zhu L, Dong Y and Tang H, J Photochem Photobiol: A Chem., 2008, 198(2-3), 282-287; DOI:10.1016/j.jphotochem.2008.03.021

12. Concalves M S T, Oliveira-Campos A M F, Pinto M M S, Plasencia P M S and Queiroz M J R P, Chemosphere, 1991, 39(5), 781-786; DOI:10.1016/S00456535(99)00013-2

13. Carp O, Huisman C L and Reller A, Solid State Chem., 2004, 32(1-2), 33-177; DOI:10.1016/j.progsolidstchem.2004.08.001

14. Coleman H M, Vimonses V, Leslie G and Amal R, J Hazard Mater., 2007, 146(3), 496-501; DOI:10.1016/j.jhazmat.2007.04.049

15. Mahmoodi N M, Arami M, Limaee N Y and Tabrizi N S, J Colloid Interface Sci., 2006, 295(1), 159-164; DOI:10.1016/j.jcis.2005.08.007 